\title{
Karakteristik Dan Sebaran Situs Kubur Tempayan Di Asia Daratan Dan Kepulauan, Kawasan Asia Tenggara
}

\section{Fadhila Arifin Aziz}

Keywords: burial, urn, jars, typology, description, distribution, pottery, prehistory

\section{How to Cite:}

Aziz, F. A. (1998). Karakteristik Dan Sebaran Situs Kubur Tempayan Di Asia Daratan Dan Kepulauan, Kawasan Asia Tenggara. Berkala Arkeologi, 18(2), 57-71. https://doi.org/10.30883/jba.v18i2.784

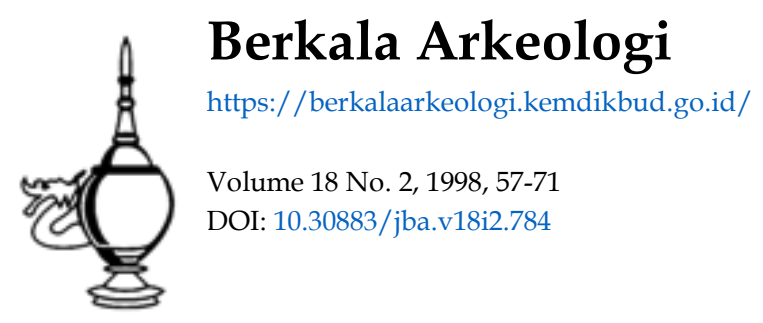

\section{c) (7) (2)}

This work is licensed under a Creative Commons Attribution-NonCommercial-ShareAlike 4.0 International License. 


\title{
KARAKTERISTIK DAN SEBARAN SITUS KUBUR TEMPAYAN \\ DI ASIA DARATAN DAN KEPULAUAN, KAWASAN ASIA TENGGARA
}

\author{
Fadhila Arifin Aziz \\ (Pusat Penelitian Arkeologi Nasional)
}

\section{Pendahuluan}

Situs kubur tempayan merupakan sebidang lahan yang digunakan sebagai lokasi penguburan dan memiliki ciri tempayan digunakan sebagai wadah untuk menempatkan jasad mayat. Jenis gerabah berbentuk tempayan memiliki rongga dengan daya muat cukup besar untuk menyimpan bahan makanan dan minuman, bahkan di beberapa situs arkeologi sisa tulang manusia atau rangka dalam posisi jongkok dimasukkan ke dalam tempayan.

Pada beberapa tempat di kawasan Asia Tenggara ditemukan situs dengan karakteristik temuan bercorak kubur tempayan baik di kepulauan, maupun daratan Asia, seperti di Jepang, Vietnam, Thailand, Filipina, dan Indonesia. Kubur tempayan di atas berkembang baik di Asia Daratan maupun Asia Kepulauan pada masa akhir paleolitik sampai masa kemahiran seni tuang perunggu-besi. Menurut Bellwood, tradisi kubur tempayan yang berlangsung di Filipina dan Serawak diperkirakan berasal sekitar 1000 BC sampai fase awal logam pada pengaruh Spanyol atau awal masehi (Bellwood, 1985:246). Sementara itu kubur tempayan di Thailand diduga berasal dari awal masehi sampai abad ke-11 Masehi, dan kubur tempayan di Indonesia diperkirakan berlangsung dari masa neolitik sampai awal Masehi (Indrawooth 1997:149).

Sebagian besar situs kubur tempayan di atas masing-masing memiliki karakteristik khusus, baik dalam cara penempatan rangka dalam tempayan, bahan yang digunakan, bentuk dan hiasan, tata letak dan penyebarannya dalam satuan lokasi, dan lain-lain. Pada beberapa situs kubur tempayan ditemukan bersama dengan kubur tanpa wadah, bahkan ada pula yang letaknya berdampingan dengan kubur-kubur dari masa berikutnya. Karya tulis ini merupakan suatu tinjauan terhadap kubur-kubur tempayan baik karakteristik maupun sebaran beberapa Situs Kubur Tempayan yang terdapat di Kawasan Asia Tenggara.

\section{Beberapa Situs Kubur Tempayan di Daratan Asia}

Berdasarkan hasil penelitian beberapa kubur tempayan yang ditemukan di daratan Asia Tenggara antara lain di Situs Ban Kan Luang, Ban Krabuang Nok, dan Muang Fa Daed Song Yang (Thailand), Situs Sa-Huynh (Vietnam). Sementara itu data 
mengenai kubur tempayan di Kamboja dan Semenanjung Malaya belum banyak diketahui.

Situs Ban Kan Luang, Propinsi Ubon Ratchathani, Situs Ban Krabuang Nok, Propinsi Nakhon Ratchasima (Lembah Mun dan Chi), dan Muang Fa Daed Song Yang. Propinsi Karasin (Thailand) ditemukan tulang tengkorak dan tulang panjang di dalam tempayan (kubur sekunder, tidak langsung) dari bahan tanah liat yang berasosiasi dengan tempayan lain berisi manik-manik (kaca), peralatan dari perunggu dan besi (cincin, gelang, dan genta). Sisa rangka ditemukan dalam satu tempayan, sedangkan tempayan lainnya berisi benda bekal kubur atau makanan. Bentuk tempayan yang digunakan sebagai wadah kubur antara lain bulat, oval, dan silindris. Tempayan tersebut biasanya ditemukan dalam satu kelompok yang terdiri atas dua sampai sepuluh tempayan. Disamping kubur tempayan tunggal beberapa diantaranya berupa sepasang tempayan bertangkup. Sepasang tempayan bertangkup yang ditemukan terdiri dari tempayan berbentuk silindris, bulat, maupun oval digunakan sebagai wadah kemudian ditutup dengan mangkuk, atau tempayan bulat dan periuk yang diletakkan terbalik. Di Situs Ban Krabuang Nok disamping kubur sekunder, juga terdapat kubur primer di dalam tempayan. Baik kubur tempayan Ban Kan Luang, Ban Krabuang Nok, maupun Fa Daed song Yang berada di sebuah bukit yang dikelilingi parit (Indrawooth 1997).

Situs Sa-Huyhn meliputi wilayah pantai sampai Delta Mekong di bagian tengah Vietnam ditemukan pula kubur tempayan bertutup. Kubur tempayan berukuran tinggi $77 \mathrm{~cm}$ dan berdiameter $14-21 \mathrm{~cm}$ ditemukan berasosiasi dengan anting-anting dari bahan batuan, tajak dari besi, manik-manik kornalean dan lain-lain. Sebagian besar artefak terbuat dari besi, sedangkan artefak yang terbuat dari perunggu berupa peralatan dan senjata (Bellwood 1985:276-278).

\section{Beberapa Situs Kubur Tempayan di Kepulauan Asia}

Situs kubur tempayan di kepulauan Asia ditemukan antara lain di Situs Daifuku, Takenouchi, Temman yama, Itokunomori (Jepang), Situs Gua Ayub, Gua Manunggul, Magala dan Lobang Jeragan, Balingasay, Batanes, dan Bato (Filipina), dan beberapa lokasi di Indonesia seperti Situs Batudewa (Bengkulu), Situs Muara Betung (Sumatera Selatan), Situs Anyer dan Situs Plawangan (Jawa), Situs Gilimanuk dan Situs Bon Dalem (Bali), Situs Sa'abang, Takalar dan Tile-tile (Sulawesi Selatan), Situs Melolo dan Lambanapu (Sumba), Situs Kolana (Alor), dan Situs Lambanapu dan Lewoloba (Flores).

Keseluruhan situs kubur tempayan di atas merupakan situs kubur tempayan tunggal maupun kubur tempayan bercampur dengan jenis kubur wadah (nekara perunggu, 
sarkofagus) atau kubur tanpa wadah. Tempayan yang dijadikan wadah kubur pada beberapa tempat menggunakan sebuah tempayan, tempayan setangkup, ataupun tempayan dengan tutup (kendi, cawan).

Di Kepulauan Jepang, pada Lembah Nara beberapa situs kubur tempayan ditemukan dari periode gerabah Jomon sampai Kofun, atau dari masa akhir Paleolitik sampai awal Masehi. Situs Daifuku berada pada sebelah baratdaya Sungai Tera dengan ketinggian $66 \mathrm{~m}$, sebelah timur Teluk Osaka. Beberapa kubur tempayan bertutup dari bahan tanah liat bakat berasal dari periode Jomon dan Yayoi (5000 BC - 300 AD) yang terdiri dari periuk di bagian atas dipangkas dengan mangkuk sebagai penutupnya ditemukan pada situs ini. Di sebelah barat Jepang, dari masa awal Yayoi, ditemukan Situs Kiridoshi dengan kubur tempayan sepasang bertangkup berasosiasi dengan benda perunggu dan perhiasan terbuat dari kaca. Sementara itu di Situs Temman pada teras Kazu, sebelah timur Gunung Temman terdapat kubur tempayan tunggal dari tanah liat bakar dari periode pertengahan Yayoi. Kubur tempayan ditemukan pula dari periode awal Kofun di Situs Itokunomori dengan benda bekal kubur benupa alat serpih (obsidian), kapak genggam, dan lancipan (Barnes 1983; Chard 1974).

Di Kepulauan Filipina, kubur tempayan ditemukan di gua-gua, baik di Pulau Luzon, Pulau Pallawan, Pulau Mindanao, dan Kepulauan Babuyan. Di Pulau Pallawan, Situs Gua Arku (Penablanca) merupakan himpunan kubur wadah tempayan dan tanpa wadah diperkirakan berasal dari $1500-500 \mathrm{BC}$, sedangkan hasil pertanggalan terhadap arang didekat kubur tempayan berasal dari $2460 \pm 80$ BP. Tempayan ini berkarinasi dengan slip berwarna merah. Di dalam wadah tempayan kubur di atas ditemukan pula sisa cangkang moluska, perhiasan gelang dari cangkang moluska dan manik-manik dari batu, gerabah, oker, alat batu, arang, dan lain-lain,

Masih di Pulau Pallawan di Pegunungan Napaga, Propinsi Sorsogon di Situs Bato ditemukan kubur tempayan tunggal sebanyak 29 buah yang berasosiasi dengan manikmanik dan gelang terbuat dari bahan kerang (air tawar dan laut), serta beliung. Beberapa tempayan diduga dibakar dalam suhu rendah, dan sama sekali tidak ditemukan hiasan kecuali berslip sehingga kemungkinan berasal dari masa awal logam besi.

Kubur tempayan tunggal ditemukan bersama dengan kubur tanpa wadah di daerah pantai Situs Balingasay, Propinsi Bolinao Pangasinan. Wadah tempayan yang digunakan sebagai kubur berupa tempayan berglasir coklat dari dinasti Ming (Cina). Sisa rangka yang berada di dalamnya merupakan rangka kanak-kanak yang dikuburkan secara sekunder (tak langsung).

Di Situs Batanes, Pulau Mindanao ditemukan pula kubur sepasang tempayan bertangkup, yaitu salah satu tempayan disusun tumpuk terbalik sebagai penutupnya 
(tutup ganda). Sisa rangka di dalamnya diberi benda bekal kubur berupa manik-manik (batu), piring, dan cincin (perunggu). Di luar kubur tempayan ditemukan pula sisa rangka yang dikuburkan tanpa menggunakan wadah.

Situs Gua Tabon di pantai barat Palawan merupakan kompleks situs arkeologi yang mengandung temuan berupa alat batu dari masa mesolitik sampai alat logam dari masa perundagian. Diantara kompleks Gua Tabon terdapat Gua Manuggul. Pada salah satu ruang gua (chamber A) tersebut ditemukan 78 kubur tempayan tunggal dan bertutup. Beberapa diantara tempayan memiliki hiasan dengan menggunakan hematit merah, dengan teknik hias tekan, gores, dan lukis dengan warna merah. Salah satu diantara tempayan yang digunakan sebagai wadah kubur memiliki hiasan tutup berbentuk perahu (ship of the dead) dan kemudian dikenal dengan sebutan "tempayan Manunggul'. Kubur tempayan di Situs Gua Manunggul ini berasosiasi dengan manikmanik dari kaca dan batuan, gelang dari kaca, kapak corong, mata panah, dan lain-lain (Jocano 1975).

Situs Gua Ayub, Pinol, sebelah selatan Cotabato, Mindanao merupakan situs yang mengandung kubur tempayan sepasang bertangkup dan bertutup dari bahan tanah liat bakar berwarna merah dan hitam. Karakteristik tempayan yang digunakan sebagai wadah kubur sekunder (tidak langsung) dari Situs Ayub adalah bagian tutup berupa bagian torso manusia atau berbentuk antropomorpik (laki-laki, dan perempuan). Di dalam tempayan tersebut sisa rangka berasosiasi dengan manik-manik dan gelang (kaca), peralatan dan hiasan dari kerang, dan mata pisau dari besi (Dizon 1996).

Di Kepulauan Indonesia, sebagian besar kubur tempayan ditemukan di daerah pantai, meskipun di beberapa tempat kubur tempayan ditemukan di daerah pegunungan. Sampai kini beberapa situs kubur tempayan yang ditemukan antara lain di Situs Muara Betung, Situs Anyer Lor, Situs Plawangan, Situs Gilimanuk, Situs Bon Dalem, Situs Melolo, Situs Lewoleba, situs Lambanapu, Situs Waibau, dan lain-lain.

Situs kubur tempayan Muara Betung terletak pada daerah pegunungan berketinggian sekitar 300-400 m dari permukaan laut di Kecamatan Ulu Musi, Kabupaten Lahat, Propinsi Sumatera selatan. Tidak jauh dari Situs Muara Betung terdapat Situs Kunduran sekitar $20 \mathrm{~km}$ ke arah Pagar Alam dengan temuan tempayan yang serupa, akan tetapi belum ditemukan sisa tulang manusia didalamnya. Secara umum letak kubur tempayan ditemukan berdampingan dengan dolmen dan kubur tanpa wadah. Sampai tahun 1996 telah ditemukan 2 kubur tempayan dari bahan tanah liat bakar, yaitu dua buah tempayan tunggal dan sepasang (bertangkup) dengan benda bekal kubur berupa fragmen periuk dan botol, disamping kubur tanpa wadah. Letak kubur tempayan berdampingan dengan dolmen maka dapat ditarik asumsi secara relatif pendukung budaya Situs Muara Betung berasal dari masa megalitik tua (Geldem 1945, Soejono 1993, Soeroso 1996). Meskipun demikian, berdasarkan temuan serpih 
dan beliung persegi, maka Soeroso menempatkan kronologi relatif Situs Muara Betung pada masa pra-logam (Soeroso 1996).

Temuan kubur tempayan sepasang bertangkup dari bahan tanah liat bakar di Pulau Jawa ditemukan di Situs Anyer Lor, Kabupaten Pandeglang, Propinsi Jawa Barat. Situs Anyer Lor berada pada tepian Teluk Sunda merupakan daerah dataran alluvial pantai yang landai. Jarak lokasi dari pantai sekitar $200 \mathrm{~m}$, dengan ketinggian $2 \mathrm{~m}$ dari permukaan air laut. Di dalam tempayan dikuburkan manusia secara primer (langsung) dengan posisi jongkok dan sekunder (tidak langsung). Beberapa rangka (dewasa, pria dan wanita) diantaranya dibekali bekal kubur berupa cawan berkaki, kendi, manikmanik (kaca dan batu), serta gelang perunggu, sedangkan beberapa ada pula yang tidak dibekali benda bekal kubur. Bentuk tempayan sebagai wadah kubur bulat bola (globular), sedangkan bagian leher dan tepiannya tidak ada. Umumnya tempayan sebagai wadah kubur berwama coklat kehitaman dengan teknik pembuatan menggunakan tangan dan roda putar. Hiasan yang ditemukan pada tempayan tersebut berupa belah ketupat dan garis-garis kecil beriring dengan tenik gores dan tekan (Haris Sukendar 1982; Aziz 1995).

Temuan kubur tempayan juga ditemukan di daerah pantai utara Jawa, yaitu Situs Plawangan, di Desa Plawangan, Kecamatan Kragan, Kabupaten Rembang, Propinsi Jawa Tengah. Pada daerah dataran alluvial pantai dengan ketinggian sekitar $4 \mathrm{~m}$ ditemukan himpunan kubur tanpa menggunakan wadah dan dengan wadah (tempayan tanah liat bakar dan nekara perunggu). Karakteristik kubur tempayan yang ditemukan di Situs Plawangan adalah kubur tempayan bertutup dan sepasang tempayan bertangkup. Kubur tempayan bertutup terdiri atas wadah tempayan berbentuk silinder warna coklat kehitaman dengan dua buah tempayan berbentuk bulat telur warna hitam keabu-abuan yang disusun tumpuk terbalik sebagai penutupnya (tutup ganda), dan dua buah tempayan berbentuk bulat bola yang ditangkupkan (sepasang tempayan bertangkup). Bentuk kubur sepasang tempayan bulat bola bertangkup tidak memiliki hiasan dengan ukuran lebih kecil daripada kubur tempayan silinder. Baik tempayan bulat silinder maupun tutup tempayan bulat telur pada sekeliling badan bagian atas terdapat hiasan berupa lubang-lubang tembus yang berjajar, sedangkan pada bagian bibimya dijumpai pola hias gores (garis silang). Bekas striasi ditemukan pada bagian atas luar, sedangkan bagian dalam tempayan dijumpai bekas pelandas dan tekanan jari tangan. Dengan demikian teknik pembuatan tempayan yang berfungsi sebagai kubur tersebut menggunakan tangan, tatap landas, dan roda putar.

Di dalam wadah tempayan silinder yang ditutup dengan dua buah tempayan ditumpuk secara terbalik terdapat sisa rangka ( 1 individu, dewasa) yang dikuburkan secara primer (langsung) dengan posisi jongkok. Sisa rangka tersebut diberi bekal kubur manik-manik (kaca dan batu) di dalam tempayan, sedangkan di luar tempayan menempel cawan bulat dan fragmen benda besi. Sementara itu di dalam wadah 
tempayan bulat bola yang ditangkupkan terdapat sisa rangka yang dikuburkan secara sekunder (tidak langsung) dengan benda bekal kubur berupa manik-manik (kaca), cawan, dan periuk. Hasil pertanggalan terhadap sisa tulang manusia menunjukkan usia absolut $302 \pm 73 \mathrm{BP}$, meskipun demikian perlu dilakukan pertanggalan baik pada kubur tempayan (silinder bertangkup, bulat bola bertangkup) maupun kubur nekara perunggu (Haris Sukendar 1982; Boedhisampurno 1991; Aziz 1995).

Situs Kubur Gilimanuk terletak di ujung sebelah barat Pulau Bali atau di pinggir pantai Teluk Gilimanuk, termasuk Desa Gilimanuk, Kecamatan Melaya, Kabupaten Jembrana, Propinsi Bali. Pada dataran aluvial pantai yang memanjang dari pinggir Teluk Gilimanuk ke arah baratdaya dengan poros melintang baratdaya - timurlaut dengan ketinggian 4--5 m, ditemukan himpunan kubur-kubur tanpa wadah dan kubur dengan wadah (tempayan dari tanah liat bakar dan sarkofagus dari batuan). Karakteritik kubur tempayan Gilimanuk adalah sepasang tempayan bertangkup (hias motif jala dan polos) berbentuk bulat bola dan berwarna coklat terletak berdampingan dengan kubur tanpa wadah dan kubur dengan wadah sarkofagus. Hasil pertanggalan absolut terhadap sisa tulang manusia dengan penguburan tanpa wadah (primer dan sekunder) menunjukkan dari waktu 60 Sebelum Masehi sampai dengan abad ke 9 Masehi. Meskipun demikian, berapa usia kubur tempayan dan kubur sarkofagus sampai kini masih belum diketahui dengan pasti.

Lebih dari 230 individu (bayi, kanak-kanak, remaja, dewasa) dikuburkan pada areal pantai seluas 53 hcktar, baik dengan cara kubur tanpa wadah (langsung) maupun dengan wadah (tempayan dan sarkofagus) dengan benda bekal kubur terdiri dari benda terbuat dari kerang (gelang), tanah liat bakar (cawan, periuk, mangkuk, pedupaan, kendi), manik-manik (kaca, kerang, terakota, batu kalsedon, emas), benda perunggu (gelang, anting-anting, cincin, mata tajak, mata tombak, mata pisau, mata pancing), sisa hewan (unggas, anjing, babi). Sebagian besar rangka di atas dibekali periuk hias tera jala.

Tempayan di bawah yang digunakan sebagai wadah kubur dengan dasar berbentuk bulat pada bagian tepiannya dipangkas, demikian pula bagian tepian tempayan-sebagai penutup. Teknik pembuatan tempayan diduga menggunakan tangan dan tatap landas. Di dalam tempayan terdapat beberapa individu (bayi, kanak,kanak, remaja, dan dewasa) yang dikuburkan secara sekunder, sedangkan pada salah satu kubur tempayan yaitu di bawah tempayan ditemukan individu dikuburkan secara sekunder dan primer (posisi tengkurap dewasa, laki-laki) (Soejono 1977; Aziz 1995; Chita 1998).

Situs kubur Bon Dalem berada pada daerah dataran alluvial pantai termasuk Kecamatan Tejakula, Kabupaten Buleleng, Bali yang berjarak 26 km sebelah timur dari Kota Singaraja. Ketinggiannya kurang lebih $25 \mathrm{~m}$ dari permukaan air laut, sedangkan kubur tempayan ditemukan sekitar $2,8 \mathrm{~m}$ dari batas tepi pantai dengan 
kedalaman 2,6 m dari permukaan tanah ketika air laut surut. Oleh karena letaknya dipengaruhi pasang surut air laut dan abrasi, maka temuan di dalam tempayan sebagian besar merupakan fragmen sisa rangka manusia (tulang dan gigi) yang tidak lengkap dan rapuh. Rangka manusia ditemukan dengan bekal kubur berupa tatal batu. Tempayan yang terbuat dari tanah liat bakar dan dijadikan wadah kubur berdinding tipis berwarna coklat kehitaman, sedangkan penutupnya berdinding tebal dengan warna coklat kekuningan (Sudiono, 1995).

Di Indonesia bagan timur kubur tempayan ditemukan di Situs Melolo, Lewoleba, Lambanapu (Sumba) dan Waibau (Flores). Kompleks kubur tempayan di Situs Melolo berada pada satuan daerah pedataran alluvial pantai, termasuk wilayah Desa Lumbu Kori, Kecamatan Rindi Unalulu, Kabupaten Sumba Timur, Propinsi Nusa Tenggara Timur. Pada areal yang berjarak $200 \mathrm{~m}$ dari pantai dengan ketinggian 3,35 $\mathrm{m}$ di atas muka laut dijumpai karakteristik kubur tempayan bertutup dari bahan tanah liat bakar (bulat bulat dan bulat telur) dengan periuk diletakkan terbalik di tengah tempayan. Diameter mulut periuk yang lebih kecil menutup mulut tempayan. Jenis tempayan sebagai wadah kubur umumnya polos, sedangkan kendi sebagai penutup mulut tempayan memiliki hiasan muka manusia dan geometris (garis, tumpal, segi empat, lingkaran, titik-titik). Tempayan ini dikerjakan dengan tangan yang dipadu dengan tatap-landas, dan penyelesaian permukaan menggunakan slip berwarna merah maupun hitam. Hasil pertanggalan absolut terhadap sisa tulang manusia menunjukkan usia $2870 \pm 60$ BP. Di dalam satu tempayan dijumpai lebih dari satu individu (bayi, kanakkanak, remaja, dewasa) yang dikuburkan secara sekunder (tak langsung). Selain sisa rangka juga ditemukan artefak beliung persegi, manik-manik (kaca dan kerang), cincin dan anting-anting perunggu, kendi, periuk serta fragmen benda perunggu dan besi.

Situs Lewoleba terletak di pantai Teluk Lewoleba, Keeamatan Lebatukan, Pulau Lembata, Kabupaten Flores Timur, Propinsi Nusa Tenggara Timur. Kubur tempayan bertutup dari bahan tanah liat bakar ditemukan letaknya berdampingan dengan kubur tanpa wadah. Di samping Situs Melolo dan Situs Lewoleba, di Sumba Timur juga ditemukan kubur tempayan di Situs Lambanapu yang terletak di tepi Sungai Kanbaniru termasuk Kecamatan Waingapu, dan berjarak $60 \mathrm{~km}$ dari Situs Melolo. Karakteristik bentuk kubur tempayan yang terbuat dari bahan tanah liat bakar dengan kendi di Situs Lambanapu ini menyerupai kubur tempayan di Situs Melolo. Demikian pula pola hias kendi berupa geometris (Chita 1998). Sayang sekali sampai kini laporan ataupun artikel mengenai situs kubur tempayan di Lambanapu dan hubungannya dengan Situs melolo secara mendalam sangat sedikit. Di Propinsi Flores Timur dilaporkan oleh penduduk setempat temuan kubur tempayan di Situs Waibau, Kecamatan Tanjung Bunga. 


\section{Estimasi dan Kronologi Absolut Situs Kubur Tempayan}

Tidak semua kubur tempayan di Asia Tenggara memiliki pertanggalan absolut. Oleh karena itu, selama ini Bellwood membandingkan aspek teknologi (tipologi bentuk dan hiasan) yang digunakan sebagai dasar untuk melihat keterkaitannya dengan kronologi relatif kubur tempayan di Asia Tenggara. Beberapa situs kubur tempayan di kepulauan Jepang berdasarkan kronologi relatif gerabah, maka kubur tempayan dari Situs Daifuku dan Situs Kiridoshi berasal dari masa awal Yayoi sekitar 300-100 BC, meskipun demikian dijumpai pula kubur tempayan yang diperkirakan berasal dari pertengahan masa Yayoi sekitar $100 \mathrm{BC}-100 \mathrm{AD}$. Situs Temman'yama juga berasal dari masa pertengahan Yayoi. Sementara itu Situs Itokunomori berasal dari masa awal Kofun sekitar abad 4 Masehi.

Di kepulauan Filipina, beberapa situs kubur tempayan berdasarkan atribut temuan logam, maka kubur tempayan di Situs Gua Ayub, Pinol, secara relatif berusia sekitar $500 \mathrm{BC}-500 \mathrm{AD}$ (Dizon, 1996:186). Meskipun demikian di Situs Balingsay, wadah tempayan berglasir coklat dari dinasti Ming (Cina) digunakan sebagai kubur schingga diduga praktek kubur tempayan masih digunakan sampai akhir sekitar abad ke-13 atau awal abad ke-14 masehi. Hasil pertanggalan radio karbon menunjukkan himpunan temuan di Situs Gua Manunggul berusia $2840 \pm 80$ BP. Jesus Peralta beranggapan usia kubur-kubur tempayan di Gua Tabon berkisar pada 500--200 BC. Berdasarkan pertanggalan radio karbon, maka R.B. Fox (1970) menempatkan tradisi kubur tempayan baik di kompleks Gua Tabon, Gua Manuggul dan lain-lain berkembang sejak masa seribu tahun sebelum masehi, atau akhir masa neolitik--awal logam. Demikian pula kubur tempayan di Thailand diduga berasal dari abad ke-8--10 AD. Bahkan di lembah Mun dan Chi, lokasi teras yang mengandung kubur tempayan dari abad 12-13 AD ditemukan pula sisa arsitektur Buddha Mahayana seperti stupa dan patung (Indrawooth 1997:150--15I).

Di kepulauan Indonesia, beberapa kubur tempayan ditemukan tersebar diberbagai tempat, mulai dari masa akhir Sebelum Masehi sampai awal Masehi. Letak kubur tempayan berdampingan dengan dolmen di Situs Muara Betung, maka dapat ditarik asumsi secara relatif pendukung budaya ini berasal dari masa megalitik tua (Geldern 1945, Soejono 1993, Socroso 1996). Meskipun demikian, berdasarkan temuan serpih dan beliung persegi, maka Soeroso menempatkan kronologi relatif Situs Muara Betung pada masa pra-logam (Soeroso 1996).

Di Situs Plawangan pertanggalan absolut baru dilakukan terhadap sisa tulang kubur primer tanpa wadah. Hasil pertanggalan terhadap sisa tulang manusia tersebut menunjukkan usia absolut $302 \pm 73$ BP. Sebagai pembanding perlu dilakukan pertanggalan baik terhadap sisa tulang pada kubur tempayan (silinder bertangkup, 
bulat bola bertangkup), maupun sisa tulang pada kubur nekara perunggu (Haris Sukendar 1982, Boedhisampurno 1991, Aziz 1995).

Usia absolut kubur tempayan yang ditemukan pada areal yang sama dengan kubur sarkofagus dan kubur tanpa wadah sampai kini belum diketahui. Meskipun demikian, hasil pertanggalan absolut terhadap sisa tulang manusia Situs Gilimanuk dengan penguburan tanpa wadah (primer dan sekunder) menunjukkan dari kurun waktu 60 Sebelum Masehi sampai dengan abad ke 9 Masehi. Sayang sekali berapa usia kubur tempayan dan kubur sarkofagus sampai kini masih belum diketahui dengan pasti, sehingga dugaan apakah kubur tempayan semasa dengan kubur sarkofagus dan kubur tanpa wadah belum dapat disimpulkan.

Estimasi berdasarkan konteks temuan rangka manusia dengan bekal kubur berupa tatal batu dan temuan kapak perunggu dari Situs Bon Dalem, kemungkinan kubur tempayan berasal dari awal masehi sampai abad ke-10. Hasil pertanggalan absolut terhadap sisa tulang manusia dari situs Melolo menujukkan usia $2870 \pm 60 \mathrm{BP}$.

Sementara itu pertanggalan relatif terhadap situs kubur tempayan di Asia Daratan, baik di Thailand (Situs Ban Kan Luang, Ban Krabuang Nok, Fa Daed Song Yang) maupun di Vietnam (Situs Sa-huynh) diduga sejak fase awal masa logam-besi sampai masa pengaruh Hindu-Buddha berkembang.

\section{Manusia Pendukung}

Manusia pendukung budaya bercorak kubur tempayan di Asia Tenggara (kepulauan dan daratan) adalah manusia modern (spesies Homo Sapiens Sapeins) yang hidup pada bagian akhir Plestosen, pasca-Plestosen sampai Holosen. Kelompok manusia modern ini sisa-sisanya ditemukan di Situs Niah (Serawak), Situs Tabon (Pallawan), Wajak (Tulungagung), dan lain-lain. Sementara itu sisa manusia yang berasal pada kala pasca-Plestosen menunjukkan kecendrungan munculnya unsur-unsur rasial, baik dari Ras Monggolid maupun Ras Australomelanesid.

Sisa-sisa manusia yang ditemukan di dalam beberapa kubur tempayan di Indonesia Barat dan bagian utara Indonesia Timur memiliki kecendrungan ciri-ciri Ras Mongoloid yang dominan, walaupun unsur Ras Australomelanesid masih tampak. Sebaliknya, di Indonesia Timur bagian selatan ciri-ciri antara Ras Mongoloid dengan Ras Australomelanesid memiliki perbedaan cukup tegas (Jacob 1978, Agoes Soeprijo 1986).

Sebagian besar kubur tempayan berisikan sisa manusia dari berbagai usia (bayi, kanak-kanak, remaja, dan dewasa) dengan jenis kelamin pria dan wanita. Biasanya 
usia muda (bayi dan kanak-kanak) dalam tempayan dikuburkan secara primer dan sekunder. Sementara itu, hampir sebagian besar usia dewasa dikuburkan secara sekunder dalam tempayan. Hanya pada tempayan berukuran besar dengan bentuk silindris yang ditemukan di Situs Plawangan (Jawa Tengah), sisa rangka berusia dewasa dalam posisi jongkok dikuburkan secara primer.

\section{VT. Kesimpulan}

Kubur tempayan yang ditemukan di daratan dan kepulauan Kawasan Asia Tenggara memiliki karakteristik berbeda dalam cara penempatan rangka, bentuk dan hiasan tempayan, penataan letak dan penyebarannya. Di dalam atau di luar tempayan yang dijadikan wadah kubur ditemukan sisa rangka, ada yang disertai dengan beberapa benda bekal kubur (perhiasan, peralatan, senjata) dan ada pula yang tanpa disertai benda bekal kubur. Tempayan yang digunakan umumnya adalah tempayan tunggal, sedangkan penggunaan tempayan sepasang secara kuantitas hanya sedikit bila dibandingkan dengan tempayan tunggal. Pada tempayan tunggal biasanya didalamnya terdapat sisa rangka yang dikuburkan secara sekunder. Meskipun demikian ada pula yang menempatkan rangka kubur primer dengan jongkok ke dalam wadah tempayan berukuran besar dan berbentuk silindris, seperti di Situs Plawangan. Sementara itu penggunaan tempayan sepasang bermacam-macam. Ada yang memanfaatkan kombinasi tempayan dengan kendi, cawan besar, bagian dasar tempayan, ataupun dua buah tempayan berukuran sama yang salah satu sisinya dipapras atau utuh. Di samping itu pada beberapa tempat ditemukan tempayan bertutup dengan hiasan berbentuk perahu seperti di Situs Gua Manunggul dan bagian torso manusia (antropomorpik) di Situs Gua Ayub (Filipina). Dalam tempayan sepasang yang dimanfaatkan sebagai wadah kubur inipun jasad dikuburkan baik dengan cara primer (semi-flexed) seperti di Situs Kiridoshi (Jepang), maupun cara sekunder seperti ditemukan di Situs Gilimanuk, Situs Plawangan, Situs Muara Betung, dan lain-lain.

Manusia pendukung budaya bercorak kubur tempayan di Asia Tenggara (kepulauan dan daratan) adalah manusia modern (spesies Homo Sapiens Sapeins) yang hidup pada bagian akhir Plestosen, pasea-Plestosen sampai Holosen. Sementara itu sisa manusia yang berasal pada kala pasca-Plestosen menunjukkan kecendrungan munculnya unsur-unsur rasial, baik dari Ras Mongolid maupun Ras Australomelanesid. Sisa manusia yang dikuburkan dalam tempayan terdiri atas usia bayi, kanak-kanak, remaja, sampai dewasa, dengan jenis kelamin pria dan wanita. Meskipun demikian, jarang sekali dalam satu situs mewakili usia, jumlah, dan jenis kelamin yang lengkap. Sebagian besar kubur tempayan biasanya ditemukan sisa rangka yang dikuburkan secara primer bagi usia bayi dan kanak-kanak. Biasanya, sisa rangka dalam kubur tempayan dengan cara penguburan sekunder hanya terdiri atas tulang tengkorak dan gigi. Meskipun demikian, pada tempayan berukuran besar 
dengan bentuk silindris ditemukan cara penguburan primer yang di dalamnya terdapat sisa rangka dalam posisi jongkok yang berusia dewasa.

Bentuk tempayan kubur terdiri atas bentuk oval, bulat, dan silindris dalam berınacammacam ukuran. Kualitas teknik dan hiasan wadah tempayan ini menunjukkan teknologi pembuatan, lokasi asal, dan periode waktu. Tempayan yang berasal dari lokasi di daratan sebagian besar memiliki hiasan tera jala, sedangkan tempayan yang berasal dari lokasi kepulauan memiliki variasi hiasan yang beraneka ragam. Kualitas tempayan dari masa logam awal lebih baik dari segi mutu maupun variasi hiasan bila dibandingkan dengan tempayan dari masa sebelumnya. Meskipun demikian lokasi penempatan kubur tempayan baik dari masa yang lebih awal maupun masa selanjutnya seringkali ditemukan di tempat yang sama, bahkan seringkali berbaur dengan kubur-kubur tanpa wadah. Oleh karena tidak semua kubur tempayan memiliki usia absolut, maka tidak dapat diperoleh gambaran sejak kapan pendukung budaya tradisi kubur tempayan, kubur nekara perungggu, kubur sarkofagus, dan kubur tanpa wadah yang ditemukan dalam areal situs yang sama digunakan. Atau, apakah ada perbedaan waktu antara kubur tempayan yang berada di dalam gua dengan kubur tempayan di daerah pantai dan pegunungan. Tampaknya permasalahan yang berkaitan dengan dimensi waktu di beberapa lokasi kubur tempayan Asia Tenggara dalam kegiatan penelitian perlu dilakukan, disamping aspek bentuk dan ruang.

Sampai kini sangat sedikit perhatian terhadap budaya yang mengembangkan tradisi kubur tempayan. Tema-tema seperti status sosial, pola distribusi, ataupun demografi belum menjadi perhatian. Tampaknya masih perlu dikembangkan minat dan penelitian terhadap obyek budaya di atas dalam kaitan dengan budaya di Asia daratan dan Asia di Kepulauan Kawasan Asia Tenggara. Memang, pengungkapan aspek budaya masa lampau dalam skala kawasan regional wilayah Asia Tenggara menjadi suatu tantangan yang cukup menarik untuk dikaji lebih mendalam. 


\section{KEPUSTAKAAN}

Aziz. Fadhila Arifin, 1990. "Analisis Kubur Situs Plawangan", dalam Proceedings Analisis Penelitian Arkeologi Plawangan, Jilid I, Pusat Penelitian Arkeologi Nasional. Jakarta, hlm 157-177.

Aziz, F. A. (1995). Situs Gilimanuk (Bali) Sebagai Pilihan Lokasi Penguburan Pada Awal Masehi. Berkala Arkeologi, 15(3), 43-46. https://doi.org/10.30883/jba.v15i3.669

Aziz, Fadhila Arifin, 1995. "Simbolisasi dalam Praktek Kubur Tempayan Masa Paleometalik:

Kajian Atas Data Konteks Kubur", dalam Berkala Arkeologi AMERT A, no. 15, Pusat Penelitian Arkeologi Nasional, Jakarta. hlm: 1-9.

Aziz. Fadhila Arifin dan Wisjachudin Faisal, 1997. "Pertanggalan Radiokarbon, Rangka Manusia Situs Gilimanuk, Bali", dalam Bulletin Arkeologi Naditira Widya, Pusat Penelitian Arkeologi Nasional, Balai Arkeologi Banjarmasin, Nomor $02 \mathrm{hlm}: 52-62$.

Bames. Gina Lee, Yayoi-Kofun, 1983. SettJement Archaeology in The Nara Basin. Japan, Dissertation, University of Michigan.

Bellwood. Peter.1985. Prehistory of the Indo-Malaysian Archipelago, Academic Press, Sydney.

Boedhisampurno. S., 1990. "Temuan Sisa Manusia dari Situs Kubur Paleometalik Plawangan. Rembang. Jawa Tengah", dalam Proceedings Analisis Penelitian Arkeologi Plawangan. Jilid II, Pusat Penelitian Arkeologı Nasional, Jakarta. hlm:125-148.

Chard, Chester S., 1974. Northeast Asia in Prehistory, The University of Wisconsin Press, Wisconsin.

Chita. Luh Kade, 1998 "Sistem Penguburan dengan Tempayan di Bali dan Nusa Tenggara Timur". makalah dalam Seminar Evaluasi Hasil Penelitian Arkeologi, Cipayung, 16-20 Februari (belum terbit).

D.D. Bintarti, 1989. "Tempayan Kubur di Indonesia", dalam Proceedings Pertemuan IImiah Arkeologi V, Ikatan Ahli Arkeologi Indonesia, Yogyakarta, Jilid I, hlm:32-45. 
Dizon, Eusebio Z., 1997. "The Anthropomorphic Pottery From Ayub Cave, Pinol. Maitum, South Cotabato, Mindanao, Philippines", Bulletin of The Indo Pacific Prehistory The Chiang Mai Papers, Volume 1. Peter Bellwood (Ed.), Indo - Pacific Prehistory Association, Canberra: Australian National University. pp: $186-196$.

Fox, Robert B. 1970. The Tabon Caves : Archaeological Explorations and Excavtions on Palawan Island, Philippines, Monograph National Museum, Number 1, Manila.

Fox,Robert B. dan Alfredo Evangelista, 1957. "The Bato Caves. Sorsogon Province. Philippines: A Preliminary Report of Jar Burial - Stone Tool Assemblage", The University of Manila Journal of East Asiatic Studies 6, pp:49_55.

Jocano, F. Landa, 1957. Philippine Prehistory : An Anthropological Overview of the Beginnings of Filipino Society and Culture, Philippine Centre for Advance, University of the Philippines System, Diliman, Quezon City.

Haris Sukendar, 1982. "Laporan Penelitian Plawangan, Jawa Tengah Tahap I dan II", Berita Penelitian Arkeologi, no. 27, Pusat Penelitian Purbakala dan Peninggalan Nasional Jakarta 1982.

1982. "Laporan Survei Pandeglang dan Ekskavasi Anyer, Jawa Barat 1979", Berita Penelitian Arkeologi, no.28, Pusat Penelitian Purbakala dan Peninggalan Nasional, Jakarta.

Heekeren, H. R van, 1956. "The Urn Cemetery at Melolo, East Sumba (Indonesia)", Berita Dinas Purbakala, No. 3, Lembaga Purbakala dan Peninggalan Nasional, Jakarta.

1956. "Notes on a Proto-Historic Urn - Burial Site at Anyer. Java", Anthropos, vol. 51, Switzerland, pp. 194-201.

Indrawooth, Phasook, 1997. "The Practice of Jar Burial in the Mun and Chi Valleys", Bulletin of The Indo-Pacific Prehistory The Chiang Mai Papers, Vol 3. Peter Bellwood (Ed. ), Indo - Pacific Prehistory Association, Canberra : Australian National University, pp. 149-152.

Legaspi, Avelino M., 1974. Bolinao: A 14 th -15 th Century Burial Sites, Museum Publication, No. 7, National Museum, Manila, Philippines. 
Santoso Soegondho, 1983. "Urn Burials from East Sumba", First van Heekeren Symposium, Yogyakarta, September 27-30 1983. Belum terbit.

Soejono, R.P, 1977. Sistim-sistim Penguburan pada Akhir Prasejarah di Bali, Disertasi, Fakultas Sastra Universitas Indonesia, Jakarta.

(ed.), "Jaman Prasejarah di Indonesia", dalam Sejarah Nasional Indonesia, Jilid I, Balai Pustaka, Jakarta, 1984.

Soeroso, Mp, 1996. "Kubur Tempayan di Wilayah Sumatera Selatan dalam Kaitannya dengan Praktek Penguburan Tempayan di Asia Tenggara: Suatu Informasi A wal", makalah dalam Seminar Prasejarah Indonesia I, Yogyakarta, 1-3 Agustus 1996 (belum terbit).

Sudiono, 1995. Penelitian Arkeometri di Situs Sembiran. Kecamatan Tejakula. Kabupaten Buleleng, Propinsi Bali, Pusat Penelitian Arkeologi Nasional, Jakarta. Belum terbit. 


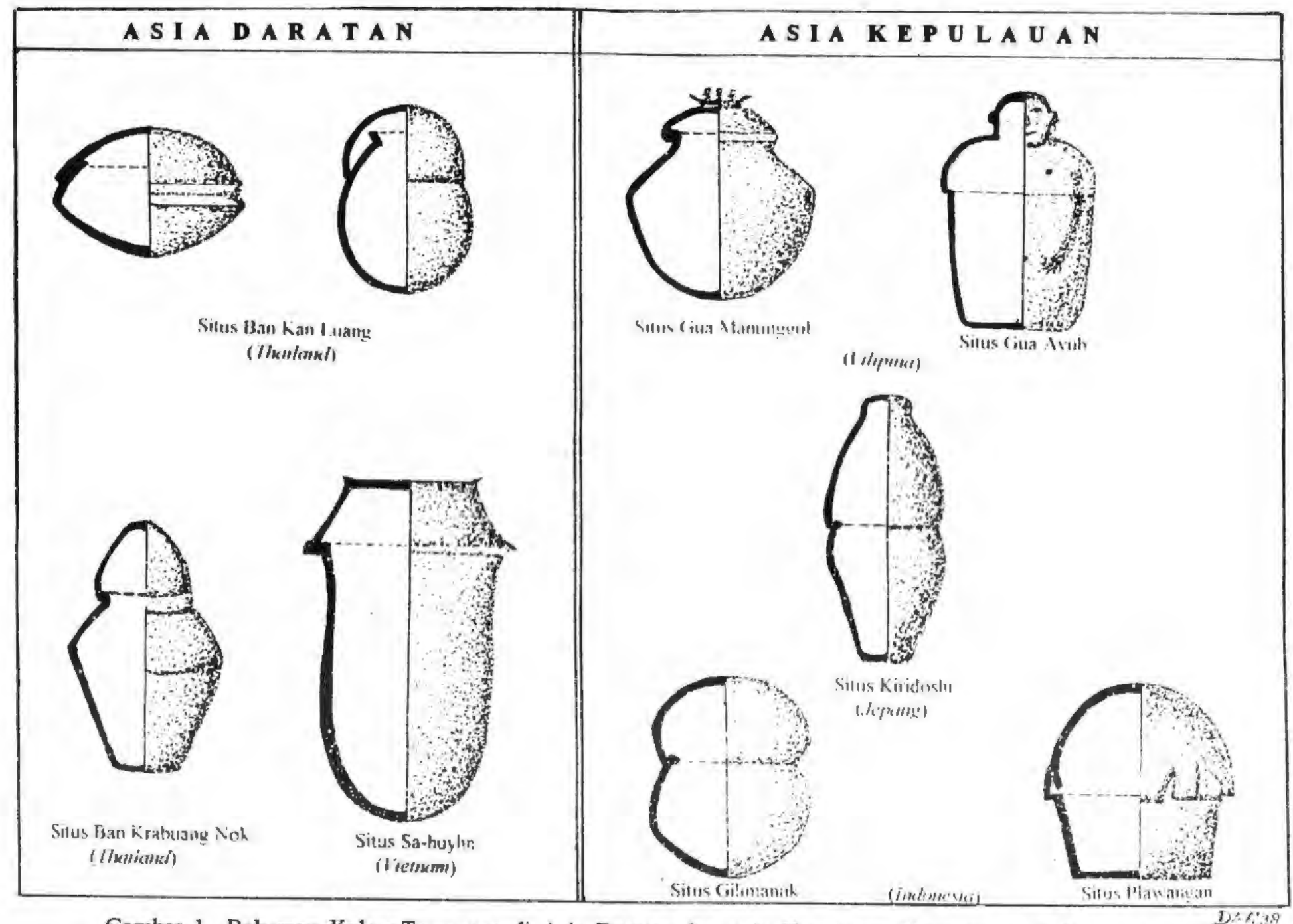

Gambar 1 Beberapa Kubur Tempayan di Asia Daratan dan Asia Kepulauan, Kawasan Asia Tenggara 